\title{
Persona EMIYA Dalam Anime Fate/Stay Night Unlimited Blade Works Karya Takahiro Miura
}

\author{
Sandhi Prasetio Atmiko \\ S1 Sastra Jepang, FIB, Universitas Jenderal Soedirman \\ Purwokerto - Jawa Tengah \\ [sandhi.bsaa@gmail.com]
}

\begin{abstract}
Abstrak
Tujuan dari penelitian ini adalah untuk mendeskripsikan persona tokoh EMIYA seperti sumber, perkembangan, dan tranformasi persona yang dialami EMIYA. Metode penelitian yang digunakan adalah deskriptif kualitatif. Teknik pengumpulan data menggunakan teknik simak catat. Teori yang digunakan adalah teori kepribadian Carl Gustav Jung mengenai arketipe persona. Hasil analisis persona EMIYA membawa kehancuran pada dirinya sendiri. EMIYA terlalu menyibukkan diri dengan dunia nya sendiri, menuruti impuls, harapan, keinginan, dan fantasi diri sendiri untuk mewujudkan ambisinya, idealisme pahlawan keadilan. EMIYA juga mengidentifikasikan diri berlebihan terhadap persona, beradaptasi dan memuaskan dunia sosial seperti membantu orang disekitarnya dengan idealisme persona pahlawan keadilannya sehingga meyakini bahwa citra yang dibangunnya adalah kepribadian sejatinya yang berakhir pada penyesalan nya karena kenyataan, tamparan takdir, situasi yang dihadapi nya berubah.
\end{abstract}

Kata Kunci: persona, Jung, anime.

\begin{abstract}
This research discusses persona EMIYA in the anime fate/stay night unlimited blade works by Takahiro Miura. The purpose of this research is to describe the persona of EMIYA's character such as the source, development, and persona transformation experienced by EMIYA. The research method used is descriptive qualitative. The data collection technique used the notetaking technique. The theory used is Carl Gustav Jung's personality theory regarding persona archetypes. The results of EMIYA's persona analysis brought destruction upon itself. EMIYA is too busy with his own world, following his own impulses, hopes, desires, and fantasies to realize his ambition, the idealism of the hero of justice. EMIYA also over-identifies with persona, adapts and satisfies the social world such as helping people around him with the idealism of his justice hero persona so that he believes that the image he builds is his true personality which ends in his regrets because reality, destiny slaps, the situation he faces changes.
\end{abstract}

Keywords: persona, Jung, anime.

\section{Pendahuluan}

Anime merupakan salah satu media hiburan animasi khas Jepang yang digambar menggunakan tangan atau teknologi komputer, memiliki berbagai macam genre untuk dinikmat. Sampai sekarang istilah anime dipakai untuk membedakan film kartun buatan Jepang dengan buatan negara lain. Pada Oxford English Dictionary, anime memiliki definisi "Japanese film and television animation, typically aimed at adults as well as children". Jadi anime dapat diartikan sebagai film dan animasi televisi Jepang yang 
ditargetkan pada orang dewasa dan juga anak-anak sebagai suatu konten hiburan. Memiliki karakteristik menampilkan aksi-aksi, karakter memiliki fitur mata yang besar, tipikal memiliki tema fantasi atau sci-fi, terkadang memiliki konten seksual atau kekerasan.

Anime dapat disebut sebagai karya sastra karena anime memiliki narasi penyerta gambar. Narasi yang muncul terkadang berupa onomatopea suara binatang, bunyi benda jatuh, desiran angin, dan sebagainya. Berkaitan dengan teks narasi (narrative text) tentu akan menyentuh bidang kesusastraan (Sobur, 2004:136). Pernyataan lain Alex Sobur yang mendukung bahwa anime tak lepas dari bidang sastra yaitu bahwa elemen pembentuk komik-kartun cukup kompleks, yakni terdiri atas unsur-unsur berbagai disiplin, misalnya bidang seni rupa, sastra, linguistik, dan sebagainya.

Jackson (2017:1) mengungkapkan bahwa anime adalah genre dimana berbagai macam isu dibahas, seperti kesakitan yang tumbuh, menemukan dan kehilangan orang yang dicinta, dan pencarian identitas. Selain itu anime juga membahas isu kekerasan, perilaku seksual, dan berbagai macam aspek shadow (sisi buruk kepribadian individu) dari pengalaman manusia. Perjuangan dalam identitas (persona) merupakan tema yang menarik perhatian saya dalam penelitian ini. Persona adalah aspek dari kepribadian yang ditunjukan kepada dunia yang mewujudkan karakteristik yang dapat diterima di masyarakat Jackson (2017:2). Persona merupakan juru bicara kepribadian. Setiap tokoh dalam anime memiliki persona nya masing - masing, yakni sisi yang diperlihatkan kepada tokoh yang lain sehingga mencerminkan persepsi mengenai peran yang harus dimainkannya dalam cerita. Tokoh dalam anime biasanya mengembangkan persona baru untuk mengantisipasi tugas apa yang akan dihadapinya. Dalam beberapa kasus, persona yang didapatkan bermanfaat, namun didalam situasi yang lain, persona itu mungkin bertanggung jawab atas jatuhnya tokoh. Melalui persona, kita mampu mempelajari psikologi suatu karakter karena memberikan gambaran untuk dipelajari.

Penelitian ini berfokus pada tokoh EMIYA yang memiliki identitas asli Shirou Emiya dari garis waktu yang berbeda, dari masa depan yang telah menjadi pahlawan seperti yang diimpikannya dengan idealisme"melindungi umat manusia tanpa harus menyebabkan kematian bagi umat manusia yang lain”. Di dalam anime Fate/Stay Night Unlimited Blade Works ini mempunyai keunikan dalam fenomena psikologis dalam hal ini yaitu perkembangan persona EMIYA. EMIYA dengan persona 正義の味方（Seigi 
no Mikata; Pahlawan Keadilan) kecewa akan idealisme nya sendiri yang telah dipercayainya sejak kecil. Dia selalu berusaha memenuhi harapan orang - orang untuk membersihkan kejahatan di dunia, membuatnya terlalu menggunakan persona dan cenderung hidup hanya untuk memenuhi harapan sosial dan akhirnya menyesali hal itu dan idealismenya yang dia anggap bodoh.

Berdasarkan permasalahan yang telah dikemukan diatas, dapat dirumuskan rumusan masalah sebagai berikut.

1) Apa sumber persona tokoh EMIYA dalam Fate/Stay Night Unlimited Blade Works?

2) Bagaimana perkembangan persona tokoh EMIYA dalam Fate/Stay Night Unlimited Blade Works?

3) Apa penyebab transformasi persona tokoh EMIYA dalam Fate/Stay Night Unlimited Blade Works?

\section{Metode dan Teori}

\subsection{Metode Penelitian}

Sumber data diambil dari anime Fate/Stay Night Unlimited Blade Works karya Takahiro Miura. Metode dan teknik yang digunakan pada penelitian ini yaitu teknik simak catat Nurhidayah (2015 dalam Nani Muftihah 2019). Metode analisis data menggunakan metode analisis naratif menurut Miles (Miles\&Huberman, 2007).

\subsection{Teori}

Terdapat dua teori yang digunakan pada makalah ini yaitu teori penokohan oleh Nurgiyantoro (2007) untuk menganalisis penokohan tokoh dan teori psikologi sastra oleh Jung (dalam Murray (2019)) mengenai persona untuk menganalisis sumber, perkembangan, dan transformasi persona tokoh EMIYA dalam anime Fate/Stay Night Unlimited Blade Works karya Takahiro Miura.

\section{Hasil dan Pembahasan}

Bagian ini membahasa mengenai penokohan dan persona tokoh EMIYA dalam anime Fate/Stay Night Unlimited Blade Works karya Takahiro Miura. Berikut merupakan pemaparan dari hasil analisis. 


\subsection{Penokohan EMIYA}

Berdasarkan teknik cakap dan reaksi tokoh, EMIYA adalah sosok yang dingin, sarkastis, dan juga terus terang namun juga perhatian yang dapat dilihat dari kutipan berikut ini.

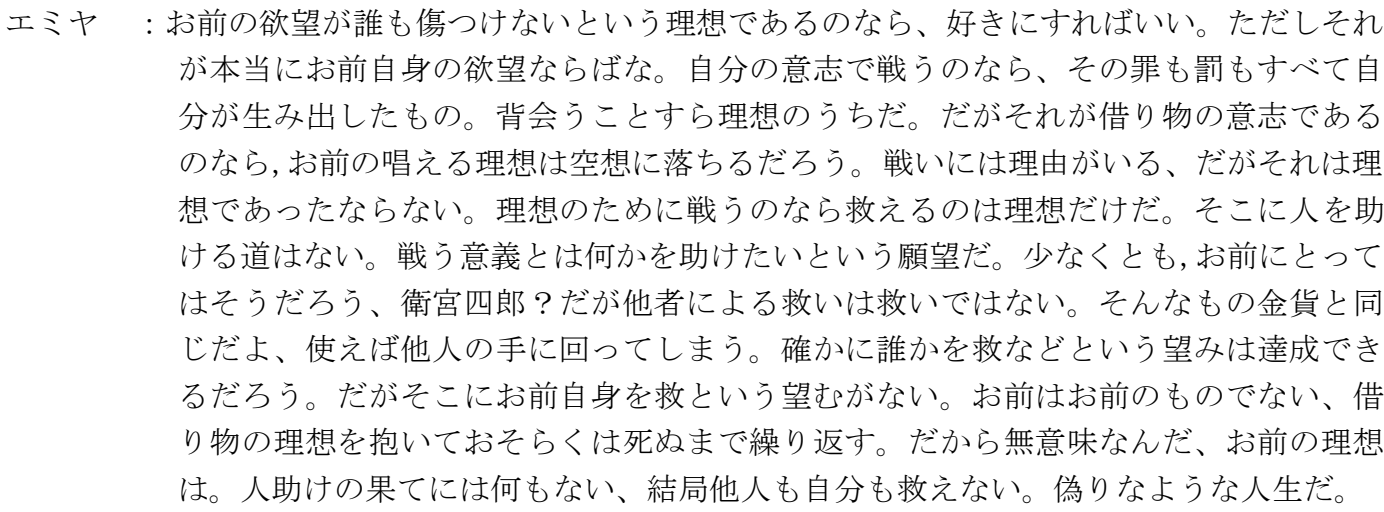

EMIYA: Omae no yokubou ga daremo kizutsukenai to iu risou de aru nara, suki ni sureba ii. Tadashi sore ga hontou ni omae jishin no yokubou naraba na. Jibun no ishi de tatakau no nara, sono tsumi mo batsu mo subete jibun ga umidashita mono. Seau koto sura risou no uchi da. Daga sore ga karimono no ishi de aru nara, omae no tonaeru risou ha kuusou ni ochiru darou. Tatakai ni wa riyuu ga iru. Daga sore wa risou de atta naranai. Risou no tame ni tatakau no nar sukueru no wa risou dake da. Soko ni hito wo tasukeru michi wa nai. Tatakau igi to ha nani ka wo tasuketai to iu ganbou da. Sukunakutomo, omae ni totte wa sou darou, Emiya Shirou? Daga tasha ni yoru sukui ha sukui de wa nai. Sonna mono kinka to onaji dayo. Tsukaeba, tanin no te ni mawatteshimasu. Tashika ni dareka wo suku nado to iu nozomi wa tassei dekiru darou. Daga soko ni omae jishin wo suku to itu nozomu ga nai. Omae wa omae no mono de nai, karimono no risou wo daite, osoraku wa shinu made kuri kaesu. Dakara muimi nanda, omae no risou wa. Hito tasuke no hate ni wa nanimo nai, kekkyoku tanin mo jibun mo sukuenai. Itsuwari no you na jinsei $d a$.

EMIYA: Kalau memang idealismemu adalah untuk tidak menyakiti siapapun, terserah dirimu. Namun jika itu benar - benar keinginanmu. Kalau kau bertarung atas keinginanmu sendiri, semua dosa dan kesalahan akan ditanggung diri sendiri. Memikul beban itu termasuk bagian dari idealisme. Tapi kalau idealisme mu adalah idealisme pinjaman, berarti idealisme yang kau pegang hanya akan menjadi fantasi belaka. Setiap pertarungan memiliki alasan. Tapi jangan jadikan alasan itu menjadi idealisme mu. Kalau kau bertarung demi idealisme mu, maka hanya itulah yang bisa kau selamatkan. Di dalamnya, tidak ada jalan 
menyelamatkan orang lain. Alasan bertarung adalah pencapaian cita cita untuk menyelamatkan sesuatu. Setidaknya itu lah yang menjadi landasanmu kan, Shirou Emiya? Tapi penyelamatan yang dilakukan oleh orang lain bukanlah penyelamatan, Hal seperti itu tidak lebih dari sekedar harta benda. Setelah digunakan, maka diberikan ke orang lain. Memang benar, mungkin keinginanmu untuk menyelamatkan orang lain bisa kau capai. Tapi dengan melakukannya, tidak ada keinginan untuk menyelamatkan dirimu sendiri. Kau bukan milikmu sendiri, memeluk idealisme pinjaman itu, mungkin sampai mati akan terus berulang. Karena itu idealisme mu tak ada artinya. Tidak ada yang kau dapat dari menyelamatkan orang lain. Dan pada akhirnya, tidak bisa menyelamatkan orang lain dan diri sendiri. Hidupmu akan dipenuhi oleh dusta.

(Episode 11, Menit Ke-00:20:15 - 00:21:46)

Kutipan di atas menunjukkan cakapan dan reaksi EMIYA terhadap Shirou mengenai idealisme yang Shirou pegang dan terkesan sarkastik, juga terkesan dingin dan terus terang terhadap Shirou bahwa cita - cita atau tujuan yang dikejar Shirou hanya akan dipenuhi dusta jika tetap memegang idealisme Pahlawan Keadilan. Secara tidak langsung juga memperlihatkan sikap perhatiannya terhadap Shirou. EMIYA adalah Shirou Emiya dari masa depan, yang juga pernah memegang idealisme itu dan menyesalinya. Dia sendiri berharap keberadaannya tidak terlahir di masa depan karena idealisme yang Shirou Emiya pegang.

Berdasarkan teknik tingkah laku, EMIYA adalah sosok yang dingin, oportunis dan perhatian seperti pada kutipan dibawah ini dengan gambar pendukung nya.

Gambar 5.1.1 Dalam episode 7

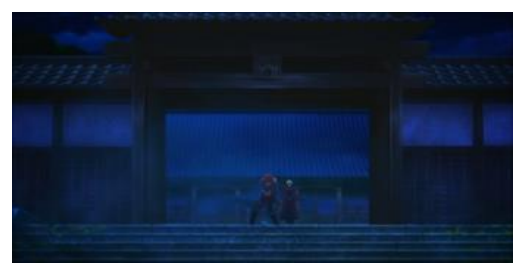

EMIYA menyerang dan menceramahi Shirou

エミヤ：戦う意義のない衛宮四郎をここで死ね。自分のためではなく誰かのために戦うなど、 ただの偽善だ。お前が望むものは勝利ではなく、平和だろう。そんなもの、この世の どこにもありはしないというのにな。 
EMIYA : Tatakau igi no nai Emiya Shirou wo koko de shine. Jibun no tame de wa naku dare ka no tame ni tatakau nado, tada no gizen da. Omae ga nozomu mono wa shouri de wa naku, heiwa darou. Sonna mono, kono yo no doko ni mo ari wa shinai to iu no ni na.

EMIYA : Matilah disini, Emiya Shirou yang tidak memiliki alasan bertarung. Bertarung demi orang lain dan bukan diri sendiri, hanyalah kemunafikan. Apa yang kau harapkan bukanlah kemenangan, tapi kedamaian. Dan hal itu, tidak akan pernah ada di dunia ini.

四郎：なん.だと！?

Shirou : Nan..dato!?

Shirou : A..pa !?

エミヤ：さらばだ。理想抱いて溺死しろ!

EMIYA : Saraba da. Risou daite dekishi shiro!

EMIYA : Selamat tinggal. Matilah bersama idealisme mu itu !

(Episode 07, Menit Ke-00:17:19 - 00:17:44)

Dari kutipan di atas dan gambar di atas, EMIYA bersikap sarkas dan dingin terhadap idealisme Shirou, menganggap bahwa Shirou adalah orang yang munafik. EMIYA adalah sosok idealisme Shirou yang telah kecewa dengan idealisme nya sendiri, sehingga dia tahu bahwa akhir dari idealisme Shirou adalah dirinya yang kecewa pada idealismenya dan menganggap bahwa hal itu munafik. Disisi lain juga menunjukkan sikap oportunis dengan memanfaatkan kesempatan untuk membunuh Shirou. Sikap perhatian dapat disimpulkan melalui dengan membunuh Shirou, maka Shirou tidak akan menderita seperti EMIYA.

Penokohan tokoh EMIYA sebagai tokoh yang dingin juga diperlihatkan melalui reaksi tokoh lain seperti kutipan berikut.

エミヤ：お前がここで何人殺そうが、私には預かり知らぬことだ。

EMIYA : Omae ga koko de nannin korosou ga, watashi ni wa azukari shiranu koto da.

EMIYA : Aku tidak peduli berapa banyak orang yang kau bunuh.

キャスター：あら。ひどい男

Caster : Ara. Hidoi otoko. 
Caster : Benar - benar pria berhati dingin

(Episode 07, Menit Ke-00:12:46 - 00:12:54)

Dari kutipan diatas merupak reaksi tokoh Caster terhadap bagaimana EMIYA bereaksi terhadap kejadian yang Caster lakukan. EMIYA tidak peduli dengan banyak nya orang yang mati karena Caster. Caster menganggap bahwa ucapan dan sikap yang EMIYA tunjukan adalah sikap yang dingin.

\subsection{Persona EMIYA}

\subsubsection{Sumber Persona EMIYA}

Asal sumber persona ada dua, yang pertama berasal dari tuntutan dan ekspektasi lingkungan, kedua berasal ambisi sosial individu tersebut. Sumber persona EMIYA ialah ambisinya untuk menjadi pahlawan keadilan meneruskan mimpi Kiritsugu Emiya ketika EMIYA masih menjadi Shirou Emiya, yang terdapat dalam kutipan dibawah ini.

四郎： 俺がわりにやってやるよ。任せろって、爺さんの夢は。

Shirou : Boku ga kawari ni yatte yaru yo. Makaserotte, Jiisan no yume wa.

Shirou : Biar aku yang menggantikanya. Serahkan saja impian pak tua padaku.

(Episode 21, Menit Ke-00:08:48 - 00:08:58)

Keinginan EMIYA untuk menjadi pahlawan keadilan juga memenuhi sumber persona yang berkaitan dengan tuntutan dan ekspektasi lingkungan, karena dalam KBBI pahlawan dijelaskan seagai orang yang menonjol karena keberanian dan pengorbanannya dalam membela kebenaran, seorang pejuang yang gagah berani. Pada saat munculnya sumber persona ini, EMIYA ingin agar tidak ada air mata di dalam dunia yang dikenalnya, membantu dan menyelamatkan orang lain, dan menginginkan hasil akhir yang dapat membahagiakan semua orang. Berikut kutipan yang menunjukkan tentang keinginan EMIYA (Shirou) untuk menjadi pahlawan.

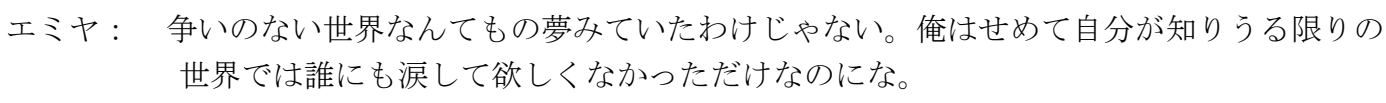


EMIYA: Arasoi no nai sekai nante mono yume miteita wake jyanai. Boku wa semete jibun ga shiriuru kagiri sekai de wa dare ni mo namida shite hoshikunakatta dake nano ni na.

EMIYA : Aku tidak bermimpi untuk dunia tanpa perselisihan. Aku hanya ingin tidak ada air mata di dalam dunia yang ku kenal selama ini.

$$
\text { (Episode 19, Menit Ke-00:10:47 - 00:11:00) }
$$

Jadi berdasarkan data diatas, dapat disimpulkan bahwa sumber persona EMIYA adalah keinginannya untuk meneruskan mimpi Kiritsugu Emiya dan menjadi pahlawan keadilan, memiliki persona sebagai orang yang baik dan suka membantu demi mewujudkan idealismenya.

\subsubsection{Perkembangan Persona EMIYA}

EMIYA adalah sosok idealisme Shirou, jadi dapat disimpulkan bahwa EMIYA mengalami perkembangan persona yang Shirou alami namun sedikit berbeda dengan Shirou dalam anime Fate/Stay Night Unlimited Blade Works namun mencapai titik dimana EMIYA berhasil mencapai idealisme nya dan menjadi pahlawan keadilan. EMIYA mengalami perkembangan Shirou dimasa lalu hingga menjadi pahlawan keadilan dengan idealismenya untuk menjadi pahlawan keadilan. Berikut merupakan kutipan yang menunjukkan bagaimana perkembangan EMIYA hingga akhir kematiannya dan menjadi Sang Pelindung, menyesali idealisme yang telah dia pegang selama ini menjadi personanya.

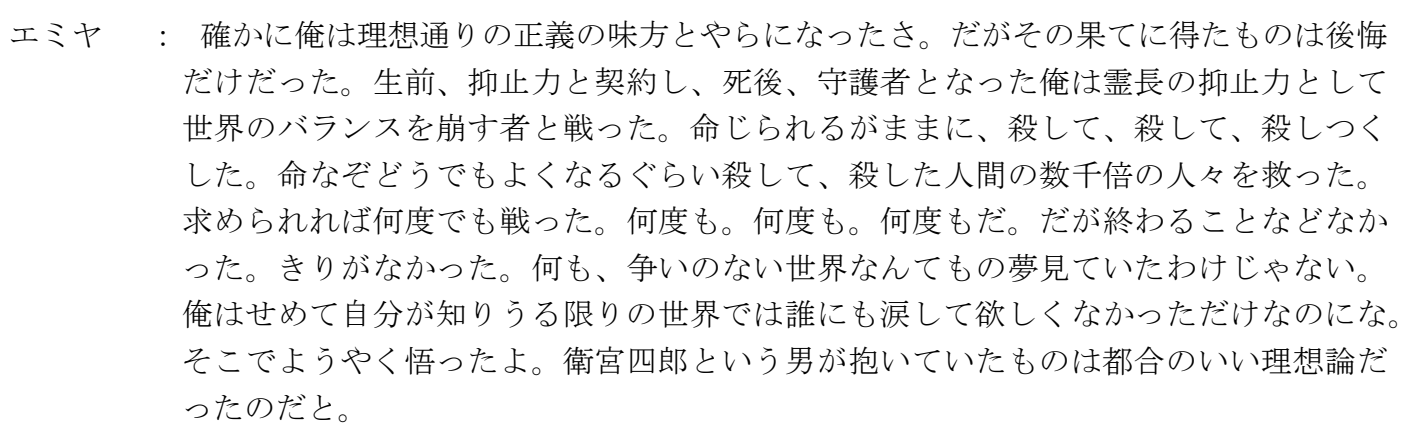

EMIYA : Tashika ni ore wa risou doori no seigi no mikata to yara ni natta. Daga sono hate ni eta mono wa kokai dake datta. Seizen, yokushiryoku to keiyaku shi, shugosha to natta ore ha reichou no yokushiryoku to shite sekai no baransu wo kuzusu mono to tatakatta, meijirare ga mama ni, koroshite, koroshite, koroshitsukushita. Inochinazo dou demo yoku naru gurai koroshite. Koroshita ningen no suusenbai no hitobito wo sukutta 
yo. Motomerarereba nando demo tatakatta. Nandomo. Nandomo. Nandomoda. Daga owaru kotonado nakatta. Kiri ga nakatta. Nanimo, arasoi no nai sekai nante mono yume miteita wakejyanai. Ore wa semete jibun ga shiri uru kagiri no sekai de wa darenimo namida shite hoshikunakatta dake nanonina. Soko de youyaku satottayo. Emiya Shirou to iu otoko ga idaiteita mono wa tsugou no ii risouron datta no da to.

EMIYA : Memang benar, aku telah berhasil menjelma menjadi sosok pahlawan keadilan sesuai idealismeku, tapi yang ku dapat di akhir hanyalah penyesalan. Semasa hidup, aku menjalin kontrak dengan Counter Force. Setelah kematian, aku menjadi Sang Pelindung, menjelma menjadi Counter Force pelindung manusia untuk melawan mereka yang merusak keseimbangan dunia. Seperti yang diperintahkan, aku membunuh, membunuh, dan terus membunuh. Saking banyaknya yang ku bunuh, aku pun tak memedulikan harga nyawa lagi. Setiap nyawa yang kuambil, aku pun menyelamatkan ribuan nyawa lainnya. Aku terus bertarung sebanyak yang diminta. Terus.. dan terus.. berulang kali. Tapi tiada akhirnya, tiada habisnya. Impianku bukanlah menginginkan dunia tanpa konflik. Aku hanya ingin tidak ada air mata di dalam dunia yang ku kenal selama ini. Dan disitulah aku sadar. Idealisme yang dijunjung oleh Shirou Emiya tidak lebih hanyalah pemikiran dangkal.

(Episode 19, Menit Ke-00:09:52 - 00:11:08)

\subsubsection{Transformasi Persona}

Transformasi persona EMIYA disebabkan karena tamparan takdir dan kenyataan yang EMIYA rasakan. Ketika EMIYA telah menjadi sang pelindung melalui kontrak dengan Counter Force, EMIYA mengira bisa menyelamatkan orang - orang, namun kenyataan nya berbeda. Ia sadar bahwa menjadi sang pelindung berarti menjadi sosok yang menjaga sejarah manusia, membunuh orang - orang yang seharusnya ia selamatkan. Ia merasa seperti seorang algojo yang membunuh manusia tanpa memandang baik atau pun benar selama itu melindungi sejarah manusia. Hal itu membuat EMIYA sadar bahwa persona, idealisme pahlawan keadilan yang ia pegang selama ini hanyalah sebuah pemikiran dangkal. Ia merasa kecewa akan idealismenya dan sudah muak memperbaiki kesalahan manusia. Kekecewaan dan penyesalan nya itu mengubah personanya, dari seorang pahlawan keadilan menjadi seorang roh pahlawan yang menyesali idealismenya. Dengan persona barunya, EMIYA terpanggil ke masa perang cawan suci ke-5, sebagai 
Archer yang menjadi persona tambahannya bertujuan untuk membunuh Shirou Emiya, berharap agar sosok EMIYA di masa depan tidak terlahir.

\section{Simpulan}

Setelah melakukan analisis terhadap persona EMIYA, penulis dapat menyimpulkan bahwa dalam penelitian ini, persona EMIYA membawa kehancuran pada dirinya sendiri. EMIYA terlalu menyibukkan diri dengan dunia nya sendiri, menuruti impuls, harapan, keinginan, dan fantasi diri sendiri untuk mewujudkan ambisinya, idealisme pahlawan keadilan. EMIYA juga mengidentifikasikan diri berlebihan terhadap persona, beradaptasi dan memuaskan dunia sosial seperti membantu orang disekitarnya dengan idealisme persona pahlawan keadilannya sehingga meyakini bahwa citra yang dibangunnya adalah kepribadian sejatinya yang berakhir pada penyesalan nya karena kenyataan, tamparan takdir, situasi yang dihadapi nya berubah.

Kemudian pemahaman sastrawan terhadap persona dapat membantu sastrawan dalam mengembangkan alur cerita karya sastranya. Selain itu, penulis juga memahami bahwa, setiap orang memiliki persona, dan persona tersebut digunakan untuk menyesuaikan diri sehingga manusia dapat berbaur dalam masyarakat.

\section{Daftar Pustaka}

Jackson, Danielle. 2017. Persona of Anime:A Depth Psychological Approach to the Persona and Individuation. California: Pacifica Graduate Institute

Muftihah, Nani. 2019. Keterampilan Berbahasa Menyimak Film. Surakarta: Universitas Sebelas Maret

Murray, Stein. 2019. JUNG'S MAP OF THE SOUL:an introduction. Yogyakarta:Shira Media

Murray, Stein. 2020. MAP OF THE SOUL:PERSONA our many faces. Yogyakarta:Shira Media

Nurgiyantorom, Burhan. 2007. TEORI PENGKAJIAN FIKSI. Yogyakarta: Gadjah Mada University Press

Sobur, Alex. 2004. ANALISIS Teks Media. Bandung: PT Remaja Rosdakarya 